\title{
Application of an evaluation method of resource and environment carrying capacity in the adjustment of industrial structure in Tibet
}

\author{
NIU Fangqu ${ }^{1,2,3}$, YANG Xinyu ${ }^{1,3},{ }^{*}$ ZHANG Xiaoping ${ }^{3}$ \\ 1. Key Laboratory of Regional Sustainable Development Modeling, Institute of Geographic Sciences and \\ Natural Resources Research, CAS, Beijing 100101, China; \\ 2. Collaborative Innovation Center for Geopolitical Setting of Southwest China and Borderland Development, \\ Kunming 650500, China; \\ 3. College of Resources and Environment, University of Chinese Academy of Sciences, Beijing 100049, China
}

\begin{abstract}
With the degradation of natural resources and environment caused by industrial development in some developing countries, the requirement of implementing a "social ecological" approach to development is imminent. Resource and environment carrying capacity provides a means of assessing regional development potential by measuring regional sustainable development in terms of economy, population and resources \& environment. This study develops a conceptual framework for resource and environment carrying capacity estimation to support the co-development planning of industries, population and resources \& environment. First, the framework constructs an index system for evaluating importance of industry or influence based on the role of industry played in the local socio-economic system. Then, the framework computes the quantitative relations through the importance of local industry, population size and resource utilization and environment effects, and subsequently estimates the resource and environment carrying capacity of the study area. With a particular attention to its land resources, water resources and environment, the Tibet case study shows that: the non-ferrous metal mining, tourism, liquor and refined tea industries play a pillar role in the Tibet's socio-economic system; under each industrial structure, land resource carrying capacity is the weakest, and water resources carrying capacity is the strongest; to focus on tourism will improve local resource and environment carrying capacity. The research results provide a solid guide for Tibet government's co-actions in industrial restructuring, ecological protection, and the pursuit of economic development. This study will contribute to bridge the gap between theoretical research and practical applications of resource and environment carrying capacity, and help local governments plan the regional "socio-ecological" sustainable development.
\end{abstract}

Keywords: resource and environment carrying capacity; industrial structure; sustainability; Tibet

Received: 2019-08-28 Accepted: 2019-10-12

Foundation: National Key Research and Development Program, No.2016YFC0503506; The Strategic Priority Research Program of the Chinese Academy of Sciences, No.XDA19040401

Author: Niu Fangqu (1979-), PhD and Associate Professor, specialized in urban and regional sustainable development modeling. E-mail: niufq@1reis.ac.cn.

"Corresponding author: Zhang Xiaoping (1972-), PhD and Associate Professor, E-mail: zhangxp@ucas.ac.cn 


\section{Introduction}

In many developing countries, rapid economic growth and explosive population growth have led to excessive resource consumption and severe environmental pollution, which has limited or affected their regional economic development. The concept of sustainable development was developed specifically to address or avoid such predicaments (Zhou et al., 2017). In order to balance the economic development and ecological protection, it has become an important issue to make scientific and reasonable decisions on the scale, progress and layout of development.

Many concepts and methods have been developed to simulate the impact of human and natural systems coupling on sustainable development. Since China's reform and opening up, it has made great achievements in rapid economic growth, large-scale industrialization and urbanization, but it has also paid a heavy resource and environmental costs. (Peng et al., 2016; Niu et al., 2018). The concept of "resource and environment carrying capacity" has been widely discussed in China. In general, resource and environment carrying capacity (RECC) refers to the upper limit of the size of the population and economy that resources and the environment can support in a given area, provided that the natural ecological environment is well maintained or not damaged.

RECC evaluation methods can be summarized into two types subject to different priorities. The first one is resource supply and demand balance method. The method focuses on the ecosystem function and characterizes the absolute size of RECC by comparing resource supply and demand from the carrier and the carrying target perspective. The resource demand analysis (Malthus, 1798; Bowen, 1954; Seidl and Tisdell, 1999; Wang et al., 2018), ecological footprint method (Rees, 1992; Wackernagel and Rees, 1996), energy analysis (Peter et al., 1986; Vitousek et al., 1986; Odum, 1988; Kitzes et al., 2008; Lou et al., 2015), and the net primary productivity method (NPP) (Thebault et al., 2008; Sutton et al., 2012) all fall into this category. The second is so-called comprehensive index method. This method reifies the ecosystem information into comprehensive indices (Mao and Yu, 2001; Fan et al., 2017) based on various theoretical frameworks such as "Pressure-State-Response (PSR)" (Wei et al., 2014; Zheng et al., 2015), "Pressure-State-Impact-Response (PSIR)" (Lockie et al., 2005) or "Driver-Pressure-Impact-Response (DPSIR)" (Cao, 2005; de Jonge et al., 2012; Li et al., 2012). The results are usually dimensionless representative values with no physical meaning. In many studies, the comprehensive indices are the carrying status rather than the potential carrying capacities. As far as the techniques are concerned, methods such as System Dynamics (SD) (Wang et al., 2014), Multi-Objective Programming model (MOP) (Wang and Zeng, 2013), and Artificial Neutral Network (ANN) (Wang et al., 2014) are used in the studies.

The common goal of these methods is to achieve a harmonious coexistence between human and the nature. These efforts have achieved certain results in research and practice. However, there have no unified paradigms for the RECC evaluation in the current domain. Moreover, the relations between social and ecological elements need deeper interpretations, and the concept and connotation of RECC needs to be further refined. More specifically, the research on the quantitative relationship between each industry and the resource $\&$ environment is still relatively weak. To solve this issue, the detailed industrial structure analysis should be considered in the RECC research. In addition, in an open regional system, due to 
the problem of cross-regional occupation, there exists an ecological pressure transfer among regions, which at present has received little attention. Furthermore, the research on the characteristics of regional industrial economy remains to be strengthened.

The interaction between natural ecosystems and local socio-economic systems requires comprehensive description and analysis. This can be quantified based on the interaction process among population, industries and resource environment. This paper aims to study the RECC and regional development potential under different industrial structures from the socio-ecological sustainability perspective. In the research the Tibet Autonomous Region as an example is comprehensively studied, in combination with the goals of eco-environmental protection and economic development targets. The goals are in three-folds: (1) to develop a conceptual framework for the general RECC evaluation; (2) to evaluate the regional RECC under different industrial structures and provide a decision-making support to achieve the maximum scale of socio-economic development under the precondition of a friendly environmental effective utilization of resources; (3) to evaluate the framework by applying it to a specific case study based on Tibet.

\section{Study area and datasets}

\subsection{Overview of the study area}

The Tibet Autonomous Region is one of the 34 provincial-level administrative regions in China. It is located in southwestern China (Figure 1) and is the second largest province with seven prefecture-level cities. Tibet has a vast territory but with a sparse population. Its administrative area is 1.23 million $\mathrm{km}^{2}$, accounting for one-eighth of the geographic expanse. However, as of 2015 , its population was $3,239,700$, only accounting for $0.24 \%$ of China's population. As of 2015, its GDP was 102.639 billion yuan, accounting for only $0.12 \%$ of China's GDP. Tibet's tertiary industry, mainly in tourism sector, is its foundational economic driver, which contributes $53.9 \%$ of its total GDP. However, in terms of the working population, the primary industry is still the largest sector, accounting for $41.2 \%$ of the workforce. Its secondary industry is the smallest sector, which employs only $13.3 \%$ of the workforce (NBSC, 2016b).

On the one hand, Tibet has a good ecological environment, primarily covered by forests, lakes and other natural ecological reserves. On the other hand, Tibet needs economic development and industrialization to alleviate poverty and achieve prosperity. However, the lessons learned from the imbalance between the two major factors in the eastern coastal region have made the Chinese government determined to achieve sustainable development under the constraints of local resources and the environment. The RECC can play an important role in

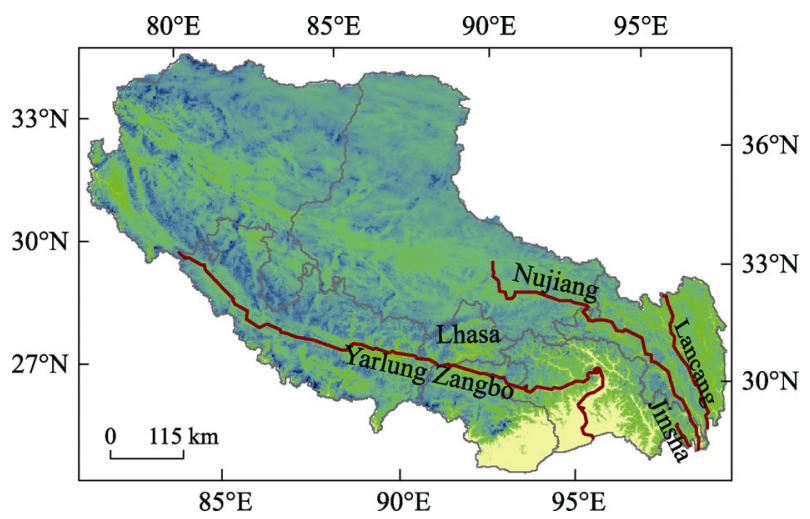

Figure 1 Study area: Tibet, China 
sustainable development planning.

\subsection{Datasets and parameters determination}

To evaluate the RECC of an open region, it is critical to investigate and determine the socio-economic burden borne by local ecological factors, especially those that cannot be transported. On the one hand, due to the land form restrictions and ecological protection in mountainous areas, the land available for development is very scarce in Tibet (Peng, 2016). On the other hand, Tibet is the birthplace of the Yarlung Zangbo River, Jinsha River, Nujiang River and Lancang River. It is rich in water resources with a reputation of Asian water tower feeding China and the Indo-China Peninsula, and its water use and quality obviously are very important for the area. Therefore, it is reasonable for this study to focus on the water and land carrying capacities evaluation of Tibet. The water carrying capacity includes two parts, namely, Water Resource Carrying Capacity and Water Environment Carrying Capacity. The former depends on the total amount of water resources available, while the latter focuses on the quality of the water environment.

The socio-economic data used in this study is collected from the Tibet Statistical Yearbook 2016 (TBS, 2016), China Statistical Yearbook 2016 (NBSC, 2016b), China Statistical Yearbook on Environment 2016 (NBSC, 2016c), China Energy Statistical Yearbook 2016 (NBSC, 2016a), and Lhasa Statistical Yearbook (LBS, 2016), and China's inter-regional Input-Output Table 2012 (Liu, 2018). Some data are obtained directly from the above sources, other data are obtained indirectly from calculation based on the above data sources. Industries are classified based on Industrial Classification for National Economic Activities of China (GB/T 4754-2017) (GAQSIQC, 2017).

\subsubsection{Water resources and consumption}

In 2015, the total amount of water available in the Tibet Autonomous Region was 385.3 billion $\mathrm{m}^{3}$. The total amount of water used is 3.08 billion $\mathrm{m}^{3}$, and the total amount of remaining water resources available is 382.22 billion $\mathrm{m}^{3}$. The water consumption includes 2.72 billion $\mathrm{m}^{3}$ for agriculture, 140 million $\mathrm{m}^{3}$ for industry, 63.61 million $\mathrm{m}^{3}$ for domestic use, and 10 million $\mathrm{m}^{3}$ for ecology, etc. (NBSC, 2016b; 2016c).

\subsubsection{Water environment capacity}

The water quality assessment generally involves the quantitative analysis of Chemical Oxygen Demand (COD), Biochemical Oxygen Demand (BOD), ammonia, phosphorus, heavy metals, organic acids, alkalis, etc. in water. The pollutants vary considerably with socio-economic activities (Zhou et al., 2017). According to China Statistical Yearbook on Environment 2016, the water pollutants in Tibet are mainly COD, so COD is used as a pollutant index in this study. The total COD emissions in Tibet in 2015 was 28,800 tons, of which industrial, agricultural, and domestic emissions are 90,000 tons, 55,000 tons, and 22,100 tons respectively.

Water Capacity $\left(W C_{y}\right)$ is calculated by the following equation:

$$
W C_{y}=\text { Ttlwater }_{y} \times W S
$$

where TtlWater $y$ is the total amount of water available in year y; WS is the water quality standard, i.e., Class I and Class II water COD is $\leqslant 15 \mathrm{mg} / \mathrm{L}$ according to Environmental 
Quality Standards for Surface Water (MEEC, 2018). As the amount of total water does not vary much over time, based on the total amount of water available in 2015, Tibet's Water Capacity by COD is 5.78 million tons, that is the COD discharged into water every year has not exceeded 5.78 million tons.

\subsubsection{Available construction land}

According to General Land Use Planning in Tibet Autonomous Region (2016-2020) (MNRC, 2017) and Tibet Statistical Yearbook 2016, as of 2020, the planned land for construction in Tibet is 164,700 ha, of which 145,000 ha is used and 19,700 ha remained for supporting further development of industry and population growth.

\section{Methods}

\subsection{RECC evaluation framework}

To evaluate the RECC, a three-step procedure is developed in the study as shown in Figure 2. First, the industry weights or importance are assessed to determine the target of the industrial adjustment. Then we analyze the socio-economic impact on resources and the environment to determine the intensity of resource consumption and the pollution emission of industries and population. Finally, the RECC under different development scenarios is estimated.

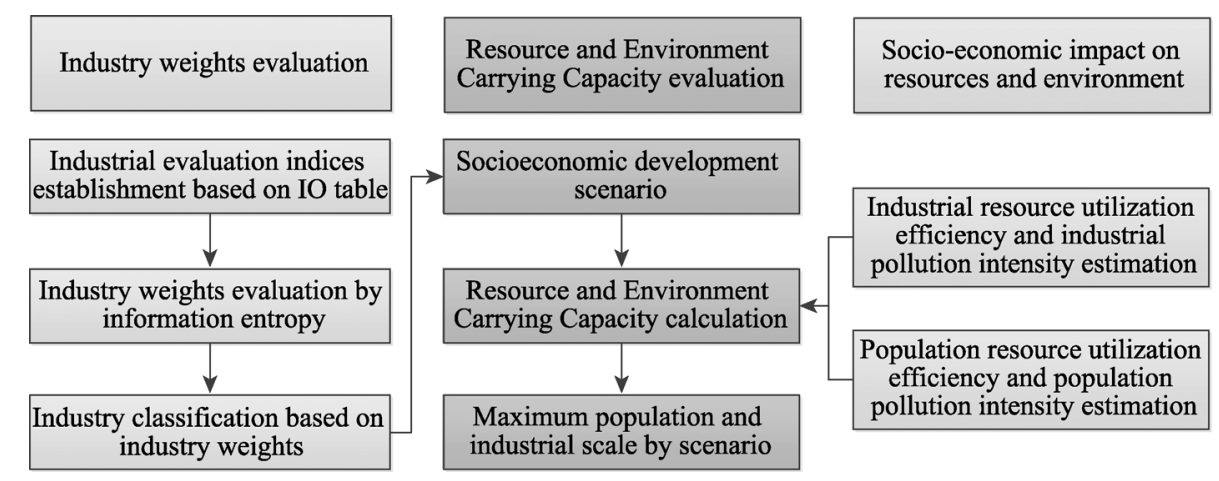

Figure 2 The RECC evaluation framework

The industry weights are assessed by ranking the contributions of industries to the local socio-economy. Four evaluation indices of industry weights, including industrial Gross Domestic Product, Industrial Influence Coefficient, Industrial Response Coefficient and Industrial Market Potential, are established. The weight or importance of each industry is calculated as the weighted sum of the four indices. The industries with high weights have greater benefits to the local socio-economic system, so are classified as pillar industries and recommended for further development.

The analysis of the regional socio-economic impact on its resource and environment is aimed at determining the intensity of resource consumption and pollution emissions by industries and population. The industrial structure and scale are the two direct factors affecting the regional resources and environment. The resource consumption and emission intensity vary with industries, so changes in industrial structure will have an important impact on the regional resource and environment. In addition to the industries, the residents also contribute to the local resource consumption and pollution emissions. 
Different development scenarios or industrial structures are developed based on the industry weights. Subsequently, the RECCs of the scenarios are calculated based on the analysis of the regional socio-economic impact on its resource and environment.

\subsection{Industry weights evaluation}

Here some industrial indices are used to represent the importance of industries to the regional economic development. These indices include industrial GDP, industrial influence coefficient (Leontief, 1941), industrial response coefficient and industrial potential, of which the industrial GDP is taken exogenously while the rest are generated by the framework endogenously as shown in the following sections.

\subsubsection{Establishment of industrial evaluation indices}

The industrial influence coefficient and response coefficient of each industry are calculated based on the Leontief inverse matrix derived from China's Input-Output (IO) Table 2012 (Liu, 2018), as attached in appendix. The industrial influence coefficient is the degree to which a unit increment of the final production of an industry affects the demands of other industries. It is the economic strength of an industry to pull other industries, calculated as:

$$
I_{j}=\frac{\sum_{i=1}^{m} l_{i j}}{\frac{1}{m} \sum_{j=1}^{m} \sum_{i=1}^{m} l_{i j}}(j=1,2, \cdots, n)
$$

where $I_{j}$ is the influence coefficient of industry $j, l_{i j}$ is the element of the Leontief inverse matrix at row $i$ and column $j, \sum_{i=1}^{m} l_{i j}$ indicates the economic influence of industry $j$ on all other industries, and the denominator $\frac{1}{m} \sum_{j=1}^{m} \sum_{i}^{m} l_{i j}$ is the average influence.

The response coefficient is the degree to which a unit increment of the finial demand of all industries affects the demand of an industry. It is the pushing power of an industry on other industries, calculated as:

$$
R_{i}=\frac{\sum_{j=1}^{m} l_{i j}}{\frac{1}{m} \sum_{i=1}^{m} \sum_{i=1}^{m} l_{i j}}(j=1,2, \cdots, n)
$$

where $R_{i}$ is the response coefficient of industry $i, \sum_{j=1}^{m} l_{i j}$ is the response of industry $i$, and $\frac{1}{m} \sum_{i=1}^{m} \sum_{i=1}^{m} l_{i j}$ is the average response.

As shown, the influence and response coefficients of an industry are calculated based on the relationship between the development status of one industry and the average development status of the other industries, through which the impact of abnormal values in the Leontief inverse matrix on the calculation is also reduced. 
The industrial market potential calculates the market advantages of an industry in a region. It takes both local and national production and market demand into account. Its relative value is calculated here as:

$$
M_{i}=\frac{S_{j}^{r}}{S_{j}^{c}} \times \frac{a S_{j}^{r}}{a S_{j}^{c}}(j=1,2, \cdots, n)
$$

where $M_{j}$ is the market potential of industry $j, S_{j}^{r}$ and $S_{j}^{c}$ are the annual regional and national sales of industry $j$ respectively while $a S_{j}^{r}$ and $a S_{j}^{c}$ are their per capita terms.

\subsubsection{Industry importance evaluation and classification}

To assess the importance or weight of an industry, we first determine the weight of each evaluation index. Here the information entropy method is employed. A smaller information entropy of an index indicates that there are greater differences between industries, so the index is more important and subject to a higher weight. The intuitive industry index matrix $X$, with $\mathrm{m}$ industries and four indices are listed in Table 1.

Table 1 Industrial evaluation index matrix

\begin{tabular}{ccccc}
\hline Industries & Output value & Influence coefficient & Response coefficient & Industrial potential \\
\hline Industry 1 & $X_{11}$ & $X_{12}$ & $X_{13}$ & $X_{14}$ \\
Industry 2 & $X_{21}$ & $X_{22}$ & $X_{23}$ & $X_{24}$ \\
Industry 3 & $X_{31}$ & $X_{32}$ & $X_{33}$ & $X_{34}$ \\
$\ldots \ldots$ & $\ldots$ & $\ldots$ & $\ldots$ & $\ldots$ \\
Industry m & $X_{\mathrm{m} 1}$ & $X_{\mathrm{m} 2}$ & $X_{\mathrm{m} 3}$ & $X_{\mathrm{m} 4}$ \\
\hline
\end{tabular}

The matrix is first normalized based on the equation

$$
x_{i j}=\frac{X_{i j}-\min \left(X_{j}\right)}{\max \left(X_{j}\right)-\min \left(X_{j}\right)}
$$

where $\max \left(X_{j}\right)$ and $\min \left(X_{j}\right)$ are the maximum and minimum values of the index $j$ respectively. Obviously, the normalized $x_{i j}$ has a range between zero and one.

The entropy $h_{j}$ of index $j$ is calculated as follows:

$$
h_{j}=\frac{1}{\ln (m)} \sum_{i=1}^{m} p_{i j} \ln p_{i j}
$$

where $1 / \ln (m)$ is a normalization factor, $p_{i j}$ is the ratio of the index $j$ of industry $i$ to the sum of index $j$ of all industries,

$$
p_{i j}=\frac{x_{i j}}{\sum_{i=1}^{m} x_{i j}}
$$

Then, the weight $W_{j}$ of index $j$ is:

$$
W_{j}=\frac{1-h_{j}}{\sum_{j=1}^{n}\left(1-h_{j}\right)}
$$

The weight $V_{i}$ of industry $i$ in the region is: 


$$
V_{i}=\sum_{j=1}^{n} x_{i j} w_{j}
$$

The weights form the basis for pillar industries identification and industrial restructuring. Tibet is currently in the early stage of industrialization, and economic and industrial development is still the important local needs. The Tibet industry weights are calculated in Table 2, where 17 industries are divided into three classes by natural breakpoint method. The first class industries which play an important role in the development of local economy are defined as pillar industries considered as the key industries for industrial structure adjustment in this study. The second class industries are defined as general industries. The third class industries are called auxiliary industries as they have minor contribution to the local economic development.

Table 2 Industry weights in Tibet, China

\begin{tabular}{|c|c|c|c|}
\hline Class & Industry type & Weight & Rank \\
\hline \multirow{3}{*}{ First Class } & Non-ferrous metal mining and dressing industry & 0.617 & 1 \\
\hline & Tourism & 0.333 & 2 \\
\hline & Wine and beverage and refined tea manufacturing industry & 0.182 & 3 \\
\hline \multirow{7}{*}{ Second Class } & Pharmaceutical industry & 0.154 & 4 \\
\hline & Chemical raw materials and chemical products manufacturing industry & 0.137 & 5 \\
\hline & Printing and recording media reproduction & 0.132 & 6 \\
\hline & Paper and paper products industry & 0.127 & 7 \\
\hline & $\begin{array}{l}\text { Culture, education, arts \& crafts, sports and entertainment products manu- } \\
\text { facturing industry }\end{array}$ & 0.127 & 8 \\
\hline & Food manufacturing & 0.118 & 9 \\
\hline & Agricultural and sideline food processing industry & 0.116 & 10 \\
\hline \multirow{7}{*}{ Third Class } & Electric power and thermal production and supply industry & 0.078 & 11 \\
\hline & Non-metallic mineral products industry & 0.074 & 12 \\
\hline & Ferrous metal mining and dressing industry & 0.053 & 13 \\
\hline & Textile industry & 0.047 & 14 \\
\hline & Wood processing and wood, bamboo, rattan, and brown grass products industry & 0.033 & 15 \\
\hline & Electrical machinery and equipment manufacturing industry & 0.030 & 16 \\
\hline & Non-metallic mining and dressing industry & 0.017 & 17 \\
\hline
\end{tabular}

\subsection{Socio-economic resource consumption and pollution discharge}

The analysis of the regional socio-economic impact on its resource and environment is aimed at determining the intensity of resource consumption and pollution emissions by industries and population, and subsequently used for the RECC evaluation.

3.3.1 Industry resource consumption and pollution discharge

The industrial impact on the resource and environment in the region is quantified by the industrial resource consumption intensity and environmental pollution intensity, i.e., the amount of resource consumption or pollution discharge per unit of GDP. Due to the limited data of Tibet, in this study the industrial resource consumption intensity and environmental pollution intensity are estimated based on national energy, water and land consumption (as 
shown in Table 3). These values are averaged for each province, so it should be of reference significance for Tibet.

Table 3 Intensities of resource consumption and pollution emission by industry

\begin{tabular}{|c|c|c|c|c|}
\hline \multirow{2}{*}{ Class } & \multirow{2}{*}{ Industry type } & \multirow{2}{*}{$\begin{array}{l}\text { Water consumption } \\
\mathrm{m}^{3} / 10^{4} \text { yuan of GDP }\end{array}$} & \multirow{2}{*}{$\begin{array}{c}\text { COD } \\
\text { discharge } \\
\mathrm{kg} / 10^{4} \text { yuan of } \\
\text { GDP }\end{array}$} & \multirow{2}{*}{$\begin{array}{c}\text { Land consump- } \\
\text { tion } \\
\text { ha } / 10^{8} \text { yuan of } \\
\text { GDP }\end{array}$} \\
\hline & & & & \\
\hline \multirow{3}{*}{ First Class } & $\begin{array}{l}\text { Non-ferrous metal mining and } \\
\text { dressing industry }\end{array}$ & 106.5 & 4.88 & 112.63 \\
\hline & Tourism & 24.63 & 9.85 & 2.88 \\
\hline & $\begin{array}{l}\text { Wine and beverage and refined } \\
\text { tea manufacturing industry }\end{array}$ & 79.4 & 12.09 & 33.19 \\
\hline \multirow{7}{*}{$\begin{array}{l}\text { Second } \\
\text { Class }\end{array}$} & Pharmaceutical industry & 48.74 & 5.44 & 15.98 \\
\hline & $\begin{array}{l}\text { Chemical raw materials and } \\
\text { chemical products manufacturing } \\
\text { industry }\end{array}$ & 100.8 & 6.37 & 35.83 \\
\hline & $\begin{array}{l}\text { Printing and recording media } \\
\text { reproduction }\end{array}$ & 19.8 & 0.32 & 1.27 \\
\hline & Paper and paper products industry & 450.33 & 90.28 & 188.41 \\
\hline & $\begin{array}{l}\text { Culture, education, arts \& crafts, } \\
\text { sports and entertainment products } \\
\text { manufacturing industry }\end{array}$ & 20.68 & 0.22 & 1.02 \\
\hline & Food manufacturing & 60.72 & 6.44 & 20.82 \\
\hline & $\begin{array}{l}\text { Agricultural and sideline food } \\
\text { processing industry }\end{array}$ & 93.73 & 12.46 & 30.59 \\
\hline \multirow{7}{*}{ Third Class } & $\begin{array}{l}\text { Electric power and thermal pro- } \\
\text { duction and supply industry }\end{array}$ & 908.46 & 0.69 & 200.00 \\
\hline & $\begin{array}{l}\text { Non-metallic mineral products } \\
\text { industry }\end{array}$ & 43.62 & 0.93 & 71.01 \\
\hline & $\begin{array}{l}\text { Ferrous metal mining and dress- } \\
\text { ing industry }\end{array}$ & 93.85 & 1.14 & 16.23 \\
\hline & Textile industry & 160.44 & 7.02 & 31.51 \\
\hline & $\begin{array}{l}\text { Wood processing and wood, } \\
\text { bamboo, rattan, and brown grass } \\
\text { products industry }\end{array}$ & 34.32 & 1.54 & 12.85 \\
\hline & $\begin{array}{l}\text { Electrical machinery and equip- } \\
\text { ment manufacturing }\end{array}$ & 11.89 & 0.18 & 0.12 \\
\hline & $\begin{array}{l}\text { Non-metallic mining and dressing } \\
\text { industry }\end{array}$ & 133.53 & 1.75 & 36.58 \\
\hline
\end{tabular}

\subsubsection{Residential resource consumption and pollution discharge}

The development of the industry is usually accompanied by increase of population, which will also lead to the increase of resource consumption and pollution emissions. In 2015, the residential living water consumption in Tibet was 63.61 million $\mathrm{m}^{3}$, i.e., $19.63 \mathrm{~m}^{3}$ per capita.

The urbanized population and land in Tibet are mainly concentrated in its provincial capital, Lhasa, where its residential land size is $24.76 \mathrm{~km}^{2}$, the residential population is 297,100 , and therefore the per capita living land is $83 \mathrm{~m}^{2}$.

In regard to water environment, the annual residential COD emission per capita $\left(p p l C O D_{t}\right)$ in year $t$ is calculated based on equation (10). 


$$
\operatorname{pplCOD}_{t}=\text { PopSew }_{t} \times a \times d
$$

where PopSew is the annual sewage production per capita in year $t, \alpha$ is the sewage discharge coefficient, and $d$ is the COD emission concentration. The daily sewage production, emission coefficient and emission concentration of residents are obtained from "First National Pollution Sources Survey - Urban Living Sources and Discharge Coefficients" (FNPC, 2008).

\subsection{Regional RECC evaluations}

\subsubsection{Water resource carrying capacity evaluation}

The water resource carrying capacity (WRCC) is the maximum population that the local water resources can support under a specific socio-economic level. At a given level, either the further developed industries, or the grown population will need to costume more resources. Here we define that the water consumption of the industry and population under the maximum load is the amount of the water available as shown by the following equations.

$$
\begin{gathered}
W_{t}=\sum_{i=1}^{m} G D P_{i, t} \times \text { inten }_{i}+\text { pop }_{t} \times \text { PopW } \\
\text { pop }_{t}=\frac{\sum_{i=1}^{m} G D P_{i, t}}{a v G D P_{t}}
\end{gathered}
$$

where $W_{t}$ is the available amount of water for production and living in year $t, \mathrm{GDP}_{i, t}$ is the GDP of industry $i$ in year $t$, inten $W_{i}$ is the consumption intensity of industry $i$ on water resource (see Table 3), pop $_{t}$ is the population size in year $t$, PopW is the population consumption intensity on water, i.e. per capita water consumption intensity, and $a v G D P_{t}$ is $G D P$ per capita in year $t$.

In general, if more than $20 \%$ of the water in a region is used, the area is considered to be short of water (Hoekstra et al., 2012; Wada, 2011). Therefore, we take $20 \%$ of the total water in Tibet as the limitation. If one assumes that the socio-economic level represented by $a v G D P_{t}$ is unchanged in short run, the maximum output of industries and size of population guided by the maximum amount of water available can be derived using the above equations.

\subsubsection{Water environment carrying capacity evaluation}

The water environment carrying capacity (WECC) assesses the maximum size of population supported by a given water quality. Both industries and residential populations produce pollution emissions. The sum of industrial and population pollution emissions is equal to the water environment capacity when the water environment is at maximum load.

$$
W E C_{c o d, t}=\sum_{i=1}^{m} G D P_{i, t} \times \text { inten }_{i}^{c o d}+\text { pop }_{t} \times P o p E^{C O D}
$$

where $W E C_{\text {cod, } t}$ is the water environment capacity in year $t$, i.e., COD capacity in this study, $\mathrm{GDP}_{i, t}$ is the GDP of industry $i$ in year $t$, pop $_{t}$ is the total population, inten $E_{i}^{\text {cod }}$ is the COD emission intensity of industry $i$ (see Table 3), and $P o p E^{C O D}$ is the emission intensity of COD of the residential population, i.e., the annual living discharge per capita (see equation 10). According to the equations 12 and 13, the industrial and population growth potentials that 
the water environment capacity can support are calculated.

\subsubsection{Land resource carrying capacity}

The Land Resource Carrying Capacity (LRCC) is the number of people that can be supported by the land resources available under specific socio-economic levels. Both the industrial development and residential population demand the land resources. The sum of the industrial land and the residential land under the maximum load is equal to the total available land resources.

$$
L_{a}=\sum_{i=1}^{m} G D P_{i, t} \times \text { inten }_{i}+\text { pop }_{t} \times P o p L
$$

where $L_{a}$ is the amount of land resources available, GDP $P_{i, t}$ is the GDP of industry $i$ in year $t$, pop $_{t}$ is the population in year $t$, inten $L_{i}$ is the intensity of land consumption of industry $i$ (see Table 3), PopL is the intensity of land resource consumption of the residential population, that is, the land resource consumption per capita. Based on the equations 12 and 14, the industrial and population growth potentials supported by land resources available can be calculated.

\section{Results}

Based on the evaluation of Tibet's industries, three industrial structure adjustment scenarios are developed. The first one is the business-as-usual scenario. We assume that the socio-economic development trend or industrial structure of Tibet remains unchanged. The second scenario is to develop the pillar industries further. The third scenario focuses on the further development of a single industry, i.e., tourism. The tourism industry is currently a vigorously developing industry with the highest output value in Tibet.

As described above, the evaluation of carrying capacity varies across different socio-economic levels which are characterized by different technical levels. The technological progress over time and its impacts on RECC is difficult to predict and quantify. This study did not include the prediction of technological progress, so for comparison between scenarios, it is assumed that they have the same technical level represented by GDP per capita, i.e. Tibet's current GDP per capita. The evaluations of RECCs are shown in Table 4.

Table 4 Regional resource and environment carrying capacity evaluation

\begin{tabular}{ccccccc}
\hline & \multicolumn{2}{c}{$\begin{array}{c}\text { Business as usual } \\
\text { (Scenario 1) }\end{array}$} & \multicolumn{2}{c}{$\begin{array}{c}\text { Focus on developing pillar } \\
\text { industries (Scenario 2) }\end{array}$} & \multicolumn{2}{c}{$\begin{array}{c}\text { Focus on developing tourism } \\
\text { (Scenario 3) }\end{array}$} \\
\cline { 2 - 7 } Carrying capacities & $\begin{array}{c}\text { Population } \\
(100 \text { million) }\end{array}$ & $\begin{array}{c}\text { Economy } \\
\text { (trillion yuan) }\end{array}$ & $\begin{array}{c}\text { Population } \\
(100 \text { million) }\end{array}$ & $\begin{array}{c}\text { Economy } \\
\text { (trillion yuan) }\end{array}$ & $\begin{array}{c}\text { Population } \\
(100 \text { million) }\end{array}$ & $\begin{array}{c}\text { Economy } \\
\text { (trillion yuan) }\end{array}$ \\
\hline WRCC & 0.81 & 2.57 & 4.87 & 15.44 & 6.48 & 20.53 \\
WECC & 2.25 & 7.41 & 1.93 & 6.11 & 2.08 & 6.58 \\
LRCC & 0.04 & 0.12 & 0.05 & 0.17 & 0.25 & 0.79 \\
\hline
\end{tabular}

The results show that the LRCC is the weakest under every scenario, indicating that the primary factor restricting the socio-economic development of Tibet is land resources (Figure 3). As a mountainous area, its construction land available is limited. The region is rich in water resources as shown, which is sufficient to support the socio-economic development of the region. In addition, the WECCs are lower than the corresponding WRCCs under scenarios 2 and 3, 
which means that with the current emission intensity unchanged, the water pollution will restrict the socio-economic development of the area despite its abundant water resources.

Using Figure 3 scenario comparisons can be implemented by RECC type. As Figure 3 shows, scenarios 2 and 3 both improve the WRCC compared with scenario 1, which can be

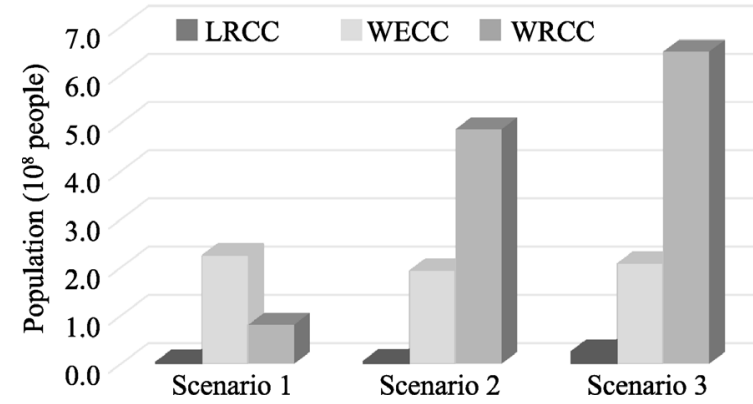

Figure 3 RECC comparisons by scenario developed as before. This indicates that the current industries have a large demand for water resources, and the adjustment of industrial structure greatly improves the utilization efficiency of the water resources, but on the other hand, the current development scenario gives the highest WECC. In regard to land resource, as opposed to the current development scenario, the other two scenarios improve the corresponding LRCCs. The reason is that the pillar industries such as non-ferrous metal mining and dressing, wine and beverage and refined tea manufacturing industries have more demand for construction land than the tourism industry. Comprehensively, the development of tourism increases Tibet's resource carrying capacity and thus boosts its economy.

\section{Conclusions and discussion}

The RECC is a typical socio-ecological system focusing on the interaction between human and nature. The proposed RECC framework develops the links between socio-economic activities and resource consumption and pollution emissions. It highlights the socio-economic effects on the resource and environment, and demands the balanced development of resource utilization, environmental protection and economic development under limited resource and environment. By taking the land resource, water resource and water environment of Tibet as cases, the study reveals that: (1) the non-ferrous metal mining, tourism, liquor and refined tea industries play a pillar role in a local socio-economic system, but pillar industries focused development may reduce the local WECC; (2) the primary factor restricting its socio-economic development is land resources; (3) developing the tourism industry enhances its RECC. The proposed framework is helpful in Tibet's actions on industrial structure adjustment and ecological protection and meanwhile pursuing economic development.

The scenarios developed in the study are not official policies. Therefore, the evaluation results can be different from the actual development. Normally, the significance of a model's results more lies in its relative evaluation rather than the absolute values (Niu and Li, 2018), in this case, compared with RECCs between various scenarios. This study develops a systematic method for regional RECC evaluation under different industrial structures, provides a guide for regional sustainable development based on the limited regional resources and environment, and helps bridge the gap between theoretical research and practical RECC applications.

There are still lots of work remaining to be explored. Due to the economic scale effect and technological advancement, the resource utilization and pollutant discharge will change along with the economic development. To achieve a finer evaluation, it is necessary to iden- 
tify the resource and environmental effects of the industries at different scales and technological levels. Secondly, as only land resource, water resource, and water environment are used as cases to implement the RECC framework, it is straightforward to integrate more ecological elements into the framework to extend the analysis framework. Furthermore, this study is carried out at the scale of the Tibet Autonomous Region because of the data limitation in this region. As Tibet is a large region, implementation of this framework at sub-region level is an exciting task, but a project of this kind will also have to overcome the problems of data availability.

\section{References}

Bowen I, 1954. Population. Cambridge: Cambridge University Press.

Cao H J , 2005. An initial study on DPSIR model. Environmental Science and Technology, 28(b06): 110-111. (in Chinese)

de Jonge V N, Pinto R, Turner R K, 2012. Integrating ecological, economic and social aspects to generate useful management information under the EU directives' 'ecosystem approach'. Ocean Coast Management, 68: $169-188$.

Fan J, Zhou K, Wang Y F, 2017. Basic points and progress in technical methods of early-warning of the national resource and environmental carrying capacity (V 2016). Progress in Geography, 36(3): 266-276. (in Chinese)

First National Pollution Census Leading Group Office of State Council (FNPC), 2008. First national pollution sources survey: Urban living sources and discharge coefficients. https:/wenku.baidu.com/view/ $6 \mathrm{ac} 5 \mathrm{eb} 145 \mathrm{fbfc} 77 \mathrm{da} 269 \mathrm{~b} 1 \mathrm{fb} . \mathrm{html}$, accessed on June 6, 2018.

General Administration of Quality Supervision, Inspection and Quarantine of China (GAQSIQC), 2017. Industrial classification for national economic activities. http://www.stats.gov.cn/tjsj/tjbz/hyflbz/201710/P020181022 345132273248.pdf, accessed in June, 2017. (in Chinese)

Hoekstra A Y, Mekonnen M M, Chapagain A K et al., 2012. Global monthly water scarcity: Blue water footprints versus blue water availability. PLoS ONE, 7(2): e32688.

Kitzes J, Wackernagel M, Loh J et al., 2008. Shrink and share: Humanity's present and future ecological footprint. Philosophical Transactions of the Royal Society B, 363: 467-475.

Leontief W W, 1941. Structure of American Economy, 1919-1929. Cambridge: Harvard University Press, Pp. xi, 181.

Lhasa Bureau of Statistics (LBS), 2016. Lhasa Statistics Yearbook. Beijing: China Statistics Press. (in Chinese)

Li T X, Fu Q, Peng S M, 2012. Evaluation of water and soil resources carrying capacity based on DPSIR frame work. Journal of Northeast Agricultural University, 43(8): 128-134. (in Chinese)

Liu W D, Tang Z P, Han M Y, 2018. The 2012 China Multi-regional Input-output Table of 31 Provincial Units. Beijing: Science Press. (in Chinese)

Lockie S, Rockloff S, Helbers D et al., 2005. A conceptual framework for selecting and testing potential social and community health indicators linked to changes in coastal resource management or condition. Coastal CRC Discussion Paper.

Lou B, Qiu Y H, Ulgiati S, 2015. Energy-based indicators of regional environmental sustainability: A case study in Shanwei, Guangdong, China. Ecological Indicators, 57: 514-524.

Malthus T R, 2001. An Essay on the Principle of Population [1st ed. of 1798]. London: Pickering.

Mao H Y, Yu D L, 2001. Regional carrying capacity in Bohai Rim. Acta Geographica Sinica, 56(3): 363-371. (in Chinese)

Ministry of Ecology and Environment of the People's Republic of China (MEEC). Environmental Quality Standards for Surface Water (GB 3838-2002). http://kjs.mep.gov.cn/hjbhbz/bzwb/shjbh/shjzlbz/200206/ t20020601_66497.shtml, Accessed on June 6, 2018. (in Chinese) 
Ministry of Natural Resources of PRC (MNRC), 2017. General Land Use Planning in Tibet Autonomous Region (2006-2020). https://wenku.baidu.com/view/6ac5eb145fbfc77da269b1fb.html, accessed on June 6, 2018. (in Chinese)

National Bureau of Statistics of China (NBSC), 2016a. China Energy Statistical Yearbook 2016. Beijing: China Statistics Press. (in Chinese)

National Bureau of Statistics of China (NBSC), 2016b. China Statistical Yearbook 2016. Beijing: China Statistics Press. (in Chinese)

National Bureau of Statistics of China (NBSC), 2016c. China Statistical Yearbook on Environment 2016. Beijing: China Statistics Press. (in Chinese)

Niu F Q, Feng Z M, Liu H, 2018. Evaluating methods of regional resources and environment carrying capacity: A review. Resources Science, 40(4): 655-663. (in Chinese)

Niu F Q, Li J, 2018. Modeling the population and industry distribution impacts of urban land use policies in Beijing. Land Use Policy, 70: 347-359.

Odum H T, 1988. Self-organization, transformity, and information. Science, 242: 1132-1139.

Peng J, Du Y Y, Liu Y X et al., 2016. How to assess urban development potential in mountain areas? An approach of ecological carrying capacity in the view of coupled human and natural systems. Ecological Indicators, 60: 1017-1030.

Peter M V, Paul R E, Anne H E et al., 1986. Human appropriation of the products of photosynthesis. BioScience, 36(6): 368-373.

Rees W E, 1992. Ecological footprints and appropriated carrying capacity: What urban economics leaves out. Environment and Urbanization, 4(2): 121-130.

Seidl I, Tisdell, C A, 1999. Carrying capacity reconsidered: From Malthus' population theory to cultural carrying capacity. Ecological Economics, 31: 395-408.

Sutton P C, Anderson S J, Tuttle B T et al., 2012. The real wealth of nations: Mapping and monetizing the human ecological footprint. Ecological Indicators, 16: 11-22.

Thebault J, Schraga T S, Cloern J E et al., 2008. Primary production and carrying capacity of former salt ponds after reconnection to San Francisco Bay. Wetlands, 28(3): 841-851.

Tibet Bureau of Statistics (TBS), 2016. Tibet Statistics Yearbook. Beijing: China Statistics Press. (in Chinese)

Vitousek P M, Ehrlich P R, Ehrlich A H et al., 1986. Human appropriation of the products of photosynthesis. BioScience, 36(6): 368-373.

Wackernagel M, Rees B, 1996. Our Ecological Footprint: Reducing Human Impact on the Earth. New Society Publishers.

Wada Y, van Beek L P H, Viviroli D et al., 2011. Global monthly water stress: Water demand and severity of water stress. Water Resource Research, 47: W07518.

Wang L, Liu H, 2019. Comprehensive evaluation of regional resources and environmental carrying capacity using a PS-DR-DP theoretical model. Journal of Geographical Sciences, 29(3): 363-376.

Wang S, Fu B, Chen H et al., 2018. Regional development boundary of China's Loess Plateau: Water limit and land shortage. Land Use Policy, 74: 130-136.

Wang S, Xu L, Yang F L et al., 2014. Assessment of water ecological carrying capacity under the two policies in Tieling City on the basis of the integrated system dynamics model. Sci. Total Environ., 472: 1070-1081.

Wang W Y, Zeng W H, 2013. Optimizing the regional industrial structure based on the environmental carrying capacity: An inexact fuzzy multi-objective programming model. Sustainability, 5(12): 5391-5415.

Wei C, Guo Z Y, Wu J P et al., 2014. Constructing an assessment indices system to analyze integrated regional carrying capacity in the coastal zones: A case in Nantong. Ocean Coast. Manag., 93: 51-59.

Zheng D F, Zhang Y, Zang Z et al., 2015. Empirical research on carrying capacity of human settlement system in Dalian City, Liaoning Province, China. Chinese Geographical Science, 25(2): 237-249.

Zhou X Y, Lei K, Meng W et al., 2017. Industrial structural upgrading and spatial optimization based on water environment carrying capacity. J. Clean. Prod., 165: 1462-1472. 